\title{
Impact of a pulmonary rehabilitation programme on respiratory parameters and health care utilization in patients with chronic lung diseases other than COPD
}

M.S. Al Moamary

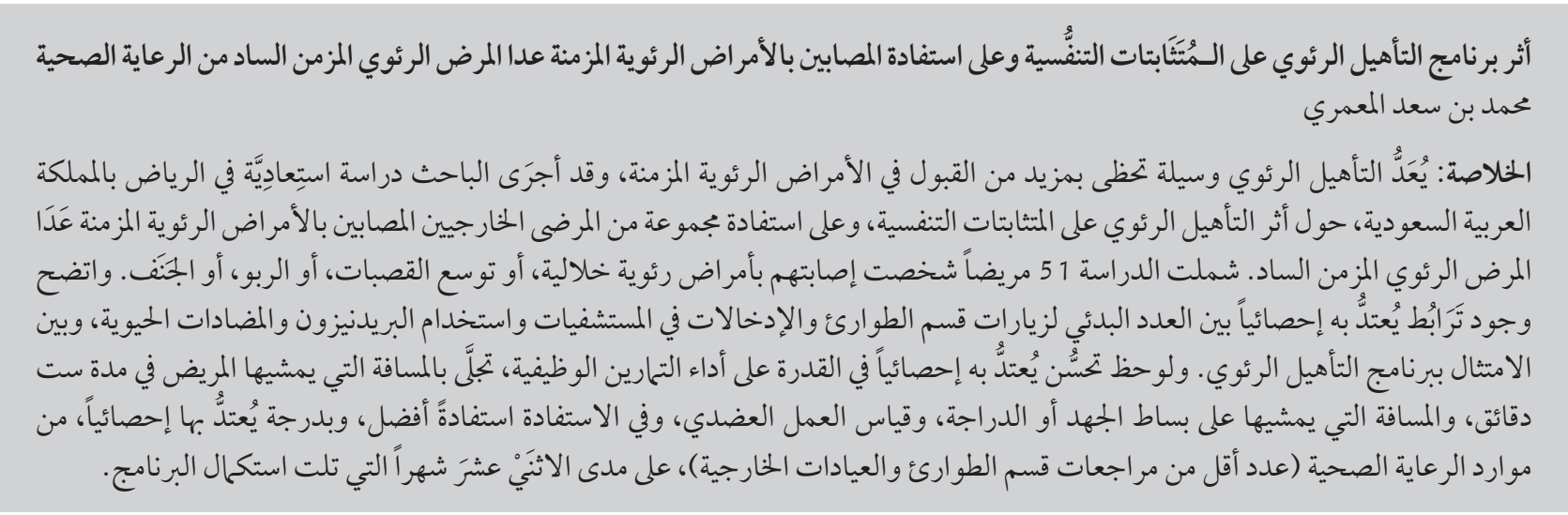

ABSTRACT Pulmonary rehabilitation is a tool that is receiving more acceptance in chronic lung diseases. A retrospective study was made in Riyadh, Saudi Arabia, on the impact of pulmonary rehabilitation on respiratory parameters and health care utilization in a group of outpatients with chronic lung diseases other than chronic obstructive pulmonary disease. A group of 51 patients diagnosed with interstitial lung diseases, bronchiectasis, asthma and scoliosis were studied. Initial number of emergency department visits and hospital admissions and use of prednisone and antibiotics were significantly associated with adherence to the pulmonary rehabilitation programme. There was a significant improvement in functional exercise capacity as manifested on the 6-minute walking distance and distance on treadmill, bicycle and arm ergometer and significantly better utilization of health care resources (fewer emergency department and outpatient department visits) over the 12 months after completion of the programme.

Impact d'un programme de rééducation pulmonaire sur les paramètres respiratoires des patients atteints d'affections pulmonaires chroniques autres que la BPCO et sur leur utilisation des soins de santé

RÉSUMÉ La rééducation pulmonaire est un outil qui est de plus en plus accepté pour les affections pulmonaires chroniques. Une étude rétrospective a été menée à Riyad (Arabie saoudite) pour connaître l'impact de la rééducation pulmonaire d'une part sur les paramètres respiratoires d'un groupe de patients en consultation externe pour des affections pulmonaires chroniques autres que la bronchopneumopathie chronique obstructive (BPCO) et d'autre part sur leur utilisation des soins de santé. Un groupe de 51 patients ayant reçu le diagnostic de maladie pulmonaire interstitielle, bronchectasie, asthme et scoliose a été étudié. Le nombre initial de visites au service des urgences et d'hospitalisations, et l'utilisation de prédnisone et d'antibiotiques étaient nettement associés à l'observance d'un programme de rééducation pulmonaire. Conformément aux résultats au test de marche de six minutes, aux tests de distance sur tapis roulant, sur bicyclette et sur ergomètre à bras, la capacité fonctionnelle à l'effort des patients s'est beaucoup améliorée et leur recours aux ressources de soins de santé a aussi été optimisée (baisse du nombre de visites au service des urgences et en consultations externes) sur une période de 12 mois, après l'achèvement du programme. 


\section{Introduction}

Pulmonary rehabilitation aims to optimize the quality of life of patients with chronic lung diseases (CLD), typically those with chronic obstructive pulmonary disease (COPD), through an individually tailored programme of education, exercise and psychosocial support [1]. Furthermore, the available evidence supports the utilization of pulmonary rehabilitation in to the management of patients with CLD other than COPD as well [2-4]. This is based on reports demonstrating increased functional exercise capacity and improved quality of life after pulmonary rehabilitation in these patients [5-8].

While data are available about the benefits of pulmonary rehabilitation in COPD in terms of reducing health care utilization $[9,10]$, Sullivan et al. indicated that there is less evidence concerning the economic consequences of premature mortality and disability associated with cases of CLD other than COPD [11]. Moreover, data on the benefits of pulmonary rehabilitation and the burden of CLD are especially scant in developing countries. A report from a university hospital in Saudi Arabia showed that one-quarter of admissions of patients with respiratory diseases were due to CLD. In this category 20\%-30\% of patients would stay in the hospital for more than 2 weeks [12]. Therefore, the objectives of the present study in Riyadh were to investigate the impact of pulmonary rehabilitation on health care utilization in a group of patients with CLD other than COPD and to identify factors that may predict adherence to the rehabilitation programme.

\section{Methods}

\section{Subjects and setting}

This retrospective study was conducted at the pulmonary rehabilitation centre at King Abdulaziz Medical City, Riyadh, Saudi Arabia. The medical records of patients referred for pulmonary rehabilitation between 1 July 2004 and 15 January 2008 were reviewed. Institutional approval for conducting the study was obtained from the institutional review board. Patient data were coded at inclusion in the database to preserve confidentiality.

This study included adult patients, aged more than 18 years, with diagnoses of bronchiectasis, severe uncontrolled asthma, interstitial lung diseases (ILD) or scoliosis. The diagnosis of ILD or bronchiectasis was confirmed by computed tomography of the chest, while spirometery and chest radiographs were used to confirm the diagnoses of asthma and scoliosis respectively. Asthma patients who had frequent visits to either the emergency department or hospital were included after a comprehensive management plan had been drawn up. Patient records were available for 12 months before the start of pulmonary rehabilitation and 12 months after the completion of pulmonary rehabilitation or the last visit (for nonadherent patients). Exclusion criteria includedincompletemedicalrecords,nonadherence to the pulmonary rehabilitation programme and lack of initial evaluation by the pulmonary rehabilitation therapist.

Patients were initially interviewed by a pulmonary rehabilitation physiotherapist as part of the initial assessment on entry in the programme. No quality of life measures were assessed as such instruments were not available in Arabic language until late 2006.

\section{Pulmonary rehabilitation}

Adherence to the pulmonary rehabilitation programme required the patient to complete the pulmonary rehabilitation protocol in the outpatient department by attending a 1-hour session, 2-3 times per week, throughout a period of 8-12 weeks for a total of 18-24 sessions. Patients were discharged from the pulmonary rehabilitation programme at 8 weeks provided that they had attended
18 sessions or until they completed 18 sessions within 8-12 weeks.

The pulmonary rehabilitation programme comprised education, exercise and psychosocial support. The exercise programme included a combination of a stationary cycle, treadmill, arm ergometer and stair stepping. The exercise programme was tailored for each patient based on their physiological parameters and the physiotherapist's judgement. Specific exercises for the upper and lower extremities were included, as well as strength and flexibility exercises. Small group education sessions were conducted by the appropriate specialist.

\section{Data collection}

Demographic data and basic physiological parameters were collected at the initial visit. This included 6-minute walking distance (6MWD) and distances logged on the treadmill, arm ergometer and bicycle. The following endpoints were recorded: number of visits to the emergency department, admissions to the hospital and number of visits to the pulmonary outpatient department. The forced expiratory volume in 1 second (FEV1) and other spirometric values were was determined using a pulmonary function machine (Jaeger Master Lab). It was calculated from the best of at least 3 trials of FEV 1 measurements after bronchodilator inhalation as per the standards of the American Thoracic Society [13]. The 6-min. walking distance followed guidelines for obtaining the best of 2 tests [14]. $\mathrm{PaO}_{2}$ and $\mathrm{PaCO}_{2}$ were measured in the laboratory using standard methods.

\section{Statistical analysis}

Continuous variables were summarized by calculating the mean and standard deviation (SD), whereas categorical variables were summarized by calculating the number and percentage. The association between different categorical variables was assessed using the chi-squared test, whereas the paired and unpaired $t$-test was used to test 
differences between continuous variables. A $P$-value of $<0.05$ was regarded as statistically significant. SPSS, version 17.0, was used for data management and analysis.

\section{Results}

A total of 51 patients with CLD other than COPD were included in this study: 21 patients $(41.2 \%)$ diagnosed with ILD, 18 (32.3\%) with bronchiectasis, $7(13.7 \%)$ with a history of severe uncontrolled asthma and 5 (9.8\%) with scoliosis.

Tables 1 and 2 show the demographic and initial physiological parameters of the study population. They comprised 15 males (29.4\%) and 36 females $(70.6 \%)$ with a male female ratio of 2.4:1 and with a mean age of 57.2 (SD 13.2) years. Of the study group, 32 patients $(62.7 \%)$ were adherent to the rehabilitation programme (Table 1 ).

Table 2 shows the patients' pattern of health care utilization 12 months prior to the pulmonary rehabilitation programme. Each patient required on average 2.0 (SD 2.4) visits to the emergency department, 1.5 (SD 4.6) admissions to the hospital and 4.3 (SD 2.3) visits to the pulmonary outpatient clinic. They also used an average of 7.1 (SD 4.5) canisters of short-acting bronchodilators, 201 (SD 287) mg cumulative doses of prednisone and 2.7 (SD 2.8) courses of antibiotics.

There was no significant difference between adherent and non-adherent patients in terms of initial physiological parameters (Table 3). However, adherent patients made a significantly higher mean number of emergency department visits [2.5 (SD 2.9) versus 1.6 (SD 1.1)] $(P=0.049)$, had significantly fewer hospital admissions $[0.1$ (SD 0.4) versus 0.4 (SD 0.7) $](P=0.034)$, used a significantly lower cumulative dose of prednisone $[117$ (SD 162) mg versus $346($ SD 386) mg] $(P<0.004)$ and had significantly fewer courses of antibiotics [2.0 (SD 2.2) versus 3.7 (SD 4.8)] (P $<0.029)$. In contrast, adherent patients made significantly more visits to the pulmonary clinic than non-adherent patients $[5.3(\mathrm{SD} 2.1)$ versus 2.6 (SD 1.4)] $(P<0.001)$.

Twelve months after completing the pulmonary rehabilitation programme, there were significant improvements in
6MWD (average increase $113 \mathrm{~m}$ ) and distance achieved on the treadmill (268 $\mathrm{m}$ increase), bicycle (1824 $\mathrm{m}$ increase) and arm ergometer ( $867 \mathrm{~m}$ increase) for the whole group of 32 adherent patients (Table 4). The differences were significant for the subgroups with ILD and bronchiectasis, although they did not reach statistical significance in patients with asthma and scoliosis. Fewer emergency department and outpatient visits as well as fewer prescriptions for short-acting bronchodilators and prednisone were also recorded 12 months after completion of pulmonary rehabilitation in the adherent group.

\section{Discussion}

In the present study we show that there was a significant improvement in functional exercise capacity 12 months after the completion of the pulmonary rehabilitation programme in a group of patients with CLD other than COPD. The improvement in functional exercise capacity was reflected by the patient's ability to walk $113 \mathrm{~m}$ longer over 6 minutes. This report also showed a positive impact on the burden of these diseases

\begin{tabular}{|c|c|c|c|c|c|c|c|c|c|c|c|}
\hline Variable & \multicolumn{2}{|c|}{$\begin{array}{l}\text { All patients } \\
\quad(n=51)\end{array}$} & \multicolumn{2}{|c|}{$\begin{array}{l}\text { Interstitial lung } \\
\text { diseases } \\
(\boldsymbol{n}=21)\end{array}$} & \multicolumn{2}{|c|}{$\begin{array}{l}\text { Bronchiectasis } \\
\qquad(n=18)\end{array}$} & \multicolumn{2}{|c|}{$\begin{array}{c}\text { Asthma } \\
(n=7)\end{array}$} & \multicolumn{2}{|c|}{$\begin{array}{l}\text { Scoliosis } \\
\quad(n=5)\end{array}$} & $P$-value \\
\hline Mean (SD) age (years) & \multicolumn{2}{|c|}{$57.2(13.2)$} & \multicolumn{2}{|c|}{$61.0(9.4)$} & \multicolumn{2}{|c|}{$56.0(16.6)$} & \multicolumn{2}{|c|}{$56.6(13.3)$} & \multicolumn{2}{|c|}{$46.2(7.9)$} & 0.148 \\
\hline Sex & No. & $\%$ & No. & $\%$ & No. & $\%$ & No. & $\%$ & No. & $\%$ & 0.038 \\
\hline Men & 15 & 29.4 & 6 & 28.6 & 5 & 27.8 & 1 & 14.3 & 3 & 60.0 & \\
\hline Women & 36 & 70.6 & 15 & 71.4 & 13 & 72.2 & 6 & 85.7 & 2 & 40.0 & \\
\hline Right ventricle abnormality & & & & & & & & & & & 0.444 \\
\hline Absent & 45 & 88.2 & 17 & 81.0 & 16 & 88.9 & 7 & 100.0 & 5 & 100.0 & \\
\hline Present & 6 & 11.8 & 4 & 19.0 & 2 & 11.1 & 0 & 0.0 & 0 & 0.0 & \\
\hline Adherence to rehabilitation programme & & & & & & & & & & & 0.496 \\
\hline Adherent & 32 & 62.7 & 11 & 52.4 & 13 & 72.2 & 4 & 57.1 & 4 & 80.0 & \\
\hline Non-adherent & 19 & 37.3 & 10 & 47.6 & 5 & 27.8 & 3 & 42.9 & 1 & 20.0 & \\
\hline $\begin{array}{l}\text { Mean (SD) duration of programme for } \\
\text { adherent patients)(days) }\end{array}$ & 66.0 & 17.4) & 65.6 & $2.2)$ & 60.9 & (21.8) & 72.8 & (16.8) & 77.0 & (10.9) & 0.355 \\
\hline $\begin{array}{l}\text { Mean }(S D) \text { no. of sessions for adherent } \\
\text { patients }\end{array}$ & 13.3 & $6.3)$ & 12.3 & & 14.3 & $6.3)$ & 12.1 & (7.7) & 15.0 & $(6.7)$ & 0.699 \\
\hline
\end{tabular}

$S D=$ standard deviation . 


\begin{tabular}{|c|c|c|c|c|c|c|}
\hline \multirow[t]{2}{*}{ Variable } & $\begin{array}{l}\text { All patients } \\
(n=51)\end{array}$ & $\begin{array}{l}\text { Interstitial lung } \\
\text { diseases } \\
(\boldsymbol{n}=21)\end{array}$ & $\begin{array}{l}\text { Bronchiectasis } \\
\quad(n=18)\end{array}$ & $\begin{array}{c}\text { Asthma } \\
(n=7)\end{array}$ & $\begin{array}{l}\text { Scoliosis } \\
(n=5)\end{array}$ & \multirow[t]{2}{*}{$P$-value } \\
\hline & Mean (SD) & Mean (SD) & Mean (SD) & Mean (SD) & Mean (SD) & \\
\hline$B M I\left(\mathrm{~kg} / \mathrm{m}^{2}\right)$ & $30.0(8.7)$ & $28.9(8.4)$ & $29.7(7.6)$ & $37.8(10.4)$ & $24.9(5.8)$ & 0.046 \\
\hline \multicolumn{7}{|l|}{ Respiratory/exercise parameters } \\
\hline $\mathrm{FEV}_{1}(\%$ of predicted $)$ & $63.4(20.4)$ & $60.3(16.9)$ & $64.3(21.7)$ & $79.4(15.8)$ & $51.2(20.4)$ & 0.081 \\
\hline FVC (\% of predicted) & $69.6(19.1)$ & $64.4(15.5)$ & $64.3(17.0)$ & $79.3(20.4)$ & $49.9(21.6)$ & 0.006 \\
\hline $\mathrm{FEV}_{1} / \mathrm{FVC}$ & $73.0(12.9)$ & $77.7(14.7)$ & $67.9(11.7)$ & $74.5(4.2)$ & $79.6(11.7)$ & 0.081 \\
\hline $\mathrm{PaO}_{2}(\mathrm{~mm} \mathrm{Hg})$ & $65.3(16.6)$ & $64.8(10.7)$ & $61.2(23.4)$ & $74.3(7.7)$ & $70.0(14.1)$ & 0.311 \\
\hline $\mathrm{PaCO}_{2}(\mathrm{~mm} \mathrm{Hg})$ & $46.7(12.9)$ & $44.5(8.2)$ & $51.4(18.2)$ & $40.4(7.4)$ & $47.4(8.4)$ & 0.203 \\
\hline 6-minute walking distance $(\mathrm{m})$ & 208 (112) & $189(95)$ & 167 (118) & 203 (129) & $227(96)$ & 0.586 \\
\hline \multicolumn{7}{|l|}{ Health care utilization } \\
\hline $\begin{array}{l}\text { Emergency department visits } \\
\text { (No.) }\end{array}$ & $2.0(2.4)$ & $1.3(1.6)$ & $2.6(2.3)$ & $3.0(4.5)$ & $1.4(1.7)$ & 0.239 \\
\hline $\begin{array}{l}\text { Admissions to the hospital } \\
\text { (No.) }\end{array}$ & $1.5(4.6)$ & $1.1(3.4)$ & $2.4(6.7)$ & $1.0(2.6)$ & $0.0(0.0)$ & 0.800 \\
\hline $\begin{array}{l}\text { Outpatient department visits } \\
\text { (No.) }\end{array}$ & $4.3(2.3)$ & $3.5(2.4)$ & $4.6(2.1)$ & $5.6(1.8)$ & $5.0(2.6)$ & 0.142 \\
\hline $\begin{array}{l}\text { Short-acting bronchodilator } \\
\text { inhalers (No.) }\end{array}$ & $7.1(4.5)$ & $7.3(4.0)$ & $8.6(5.4)$ & $9.3(2.3)$ & $5.4(3.3)$ & 0.065 \\
\hline $\begin{array}{l}\text { Cumulative prednisone dose } \\
\text { (mg) }\end{array}$ & $201(287)$ & $163(246)$ & 249 (342) & $213(322)$ & $170(232)$ & 0.824 \\
\hline Antibiotic courses (No.) & $2.7(2.8)$ & $3.0(3.3)$ & $3.2(2.8)$ & $1.3(1.8)$ & $1.4(1.3)$ & 0.332 \\
\hline
\end{tabular}

$S D=$ standard deviation

$B M I=$ body mass index; $F E V I=$ forced expiratory volume in $7 \mathrm{sec} ; F V C=$ forced vital capacity;

$\mathrm{PaO}_{2}=$ partial pressure of oxygen in the arterial blood; $\mathrm{PaCO}_{2}=$ partial pressure of carbon dioxide in the blood.

as manifested by reduced lengths of hospital stay, fewer emergency department and outpatient visits and fewer prescriptions for short-acting bronchodilator inhalers, antibiotics and prednisone. Additionally, the health care utilization pattern of patients prior to pulmonary rehabilitation may predict their adherence to the programme.

Because there is no standardized rehabilitation protocol for non-COPD diseases, the patients in this study were offered the same exercise training programme recommended to COPD patients. The other components of education and psychosocial support were customized to offer knowledge related to each disease category. Almost two-thirds of the study group (62.7\%) was adherent to the rehabilitation programme. When compared with adherent patients, patients in the nonadherent group tended to have more emergency department visits, admissions to the hospital and prescriptions for prednisone and antibiotics. Therefore, our findings suggest that patients' behaviour may predict adherence. Although patients with ILD had lower adherence, those who completed the pulmonary rehabilitation programme clearly benefited. This was in contrast of a randomized controlled study conducted by Holland et al. which reported adherence of more than $80 \%$ in a group of ILD patients [15].

Nishiyama et al. showed a significant improvement by $46.3 \mathrm{~m}$ in the $6 \mathrm{MWD}$ in a group of patients with idiopathic pulmonary fibrosis with FVC of $68 \%$ and baseline 6MWD of $476 \mathrm{~m}$ [6]. Another study found an improvement of $65 \mathrm{~m}$ in the 6MWD in a group of 99 patients with FVC of $62 \%$ and baseline 6MWD of $335 \mathrm{~m}$ [16]. In the current study, the mean of the improvement in
6MWD was 113 meters, while the baseline FVC was $64 \%$ and initial $6 \mathrm{MWD}$ was $179 \mathrm{~m}$. There were also significant improvements in the distance achieved on the treadmill, arm ergometer and bicycle. In patients with ILD, exercise limitations can be due to a number of different mechanisms: limited ventilation, gas exchange, diffusion and circulation [17]. Although there was greater improvement in 6MWD, patients with ILD in this study had lower baseline values compared with previous studies, despite comparable FVC. This can be explained by the dependence of the local community on using cars for most of their activities of daily living, leading to low training intensity with consequent deconditioning of the muscles of ambulation, a finding that was observed in patients with COPD from Saudi Arabia $[18,19]$. Moreover, patients with lower FEC values may have more room for 


\begin{tabular}{|c|c|c|c|}
\hline Variable & $\begin{array}{l}\text { Adherent } \\
(n=32)\end{array}$ & $\begin{array}{l}\text { Non-adherent } \\
\quad(n=19)\end{array}$ & $P$-value \\
\hline Mean (SD) age (years) & $55.9(14.1)$ & $59.2(11.6)$ & 0.40 \\
\hline \multicolumn{4}{|l|}{ Sex [no. (\%) of patients] } \\
\hline Men & $9(28.1)$ & $6(31.6)$ & \\
\hline Women & $23(71.9)$ & $13(68.4)$ & 0.791 \\
\hline \multicolumn{4}{|l|}{ Right ventricle abnormality [no. (\%) of patients] } \\
\hline Absent & $29(90.6)$ & $16(84.2)$ & \\
\hline Present & $3(9.4)$ & $3(15.8)$ & 0.489 \\
\hline \multicolumn{4}{|c|}{ Respiratory/exercise parameters [mean (SD) values] } \\
\hline BMI $\left(\mathrm{kg} / \mathrm{m}^{2}\right)$ & $29.5(8.2)$ & $30.9(9.7)$ & 0.587 \\
\hline $\mathrm{FEV}_{1}(\%$ of predicted $)$ & $62.3(21.3)$ & $63.1(19.0)$ & 0.892 \\
\hline FVC (\% of predicted) & $67.4(19.2)$ & $73.2(19.0)$ & 0.301 \\
\hline $\mathrm{PaO}_{2}(\mathrm{~mm} \mathrm{Hg})$ & $47.5(15.2)$ & $45.3(8.0)$ & 0.563 \\
\hline $\mathrm{PaCO}_{2}(\mathrm{~mm} \mathrm{Hg})$ & $65.4(19.5)$ & $65.0(11.0)$ & 0.987 \\
\hline 6-min. walking distance $(\mathrm{m})$ & $226(111)$ & $174(112)$ & 0.108 \\
\hline Distance on treadmill (m) & $120(80)$ & $124(80)$ & 0.849 \\
\hline Distance on bicycle (m) & $1041(440)$ & $1011(498)$ & 0.823 \\
\hline Distance on ergometer (m) & $525(154)$ & $573(255)$ & 0.410 \\
\hline \multicolumn{4}{|l|}{ Health care utilization [mean (SD) values] } \\
\hline Emergency department visits (no.) & $2.5(2.9)$ & $1.6(1.1)$ & 0.049 \\
\hline Admissions to the hospital (no.) & $0.1(0.4)$ & $0.4(0.7)$ & 0.034 \\
\hline Outpatient department visits (no.) & $5.3(2.1)$ & $2.6(1.4)$ & $<0.001$ \\
\hline Short-acting bronchodilator inhalers (no.) & $7.3(5.0)$ & $6.6(3.7)$ & 0.619 \\
\hline Cumulative prednisone dose (mg) & $117(162)$ & $346(386)$ & 0.004 \\
\hline Antibiotics courses (no.) & $2.0(2.2)$ & $3.7(4.8)$ & 0.029 \\
\hline
\end{tabular}

$B M I=$ body mass index; $F E V I=$ forced expiratory volume in $1 \mathrm{sec} ; \mathrm{FVC}=$ forced vital capacity; $\mathrm{PaO}_{2}=$ partial pressure of oxygen in the arterial blood; PaCO $=$ partial pressure of carbon dioxide in the blood.

improvement. This is supported by the finding that muscle strength is considered a good predictor of exercise tolerance [18].

Similar benefits were observed in patients with bronchiectasis as for those with ILD, with an average improvement in 6-min. walking distance of $115.7 \mathrm{~m}$. Though bronchiectasis patients had comparable FEV1 and FVC to patients with ILD, patients with bronchiectasis had better initial baseline values for the 6MWD. Newall et al. showed in a randomized controlled study that patients with bronchiectasis had a significant improvement of $97 \mathrm{~m}$ in the shuttle walking test after a standard pulmonary rehabilitation programme [7]. Patients with bronchiectasis share many of the characteristics of those with COPD, such as impairments of pulmonary and peripheral muscles function, as well as nutritional and psychological deficits $[8,18]$.

Patients with scoliosis and asthma had higher baseline levels and greater improvements in 6MWD as compared with patients with ILD and bronchiectasis. These changes did not reach statistical significance, probably due to the small sample size. However, there were significant improvements observed in the distance achieved on the treadmill, arm ergometer and bicycle. Patients with asthma showed an improvement of $117 \mathrm{~m}$ on the $6 \mathrm{MWD}$; while patients with scoliosis improved by $100 \mathrm{~m}$. Alves et al. described an improvement of 126 $\mathrm{m}$ in a group of patients with scoliosis [20]. Exercise limitations in patients with scoliosis are mainly attributed to restriction of lung volume due to spinal deformities.

In this study, clear benefits for patient with CLD were observed after completion of the pulmonary rehabilitation programme, which was reflected in subsequent health care utilization. Both emergency department and outpatient visits were significantly decreased over the 12 months following the programme compared with the period prior to the programme. Differences in the number of emergency department visits did not reach statistical significance when stratified based on disease, a finding that indicates the need for larger studies to confirm these results. On the other hand, the prescription pattern improved, based on the consumption 


\begin{tabular}{|c|c|c|c|c|c|}
\hline \multirow[t]{2}{*}{ Variable } & $\begin{array}{l}\text { All patients } \\
\quad(n=32)\end{array}$ & $\begin{array}{l}\text { Interstitial lung } \\
\text { diseases } \\
(n=11)\end{array}$ & $\begin{array}{l}\text { Bronchiectasis } \\
\quad(n=13)\end{array}$ & $\begin{array}{c}\text { Asthma } \\
(n=4)\end{array}$ & $\begin{array}{l}\text { Scoliosis } \\
\quad(n=4)\end{array}$ \\
\hline & Mean (SD) & Mean (SD) & Mean (SD) & Mean (SD) & Mean (SD) \\
\hline \multicolumn{6}{|c|}{ 6-min. walking distance $(m)$} \\
\hline Pre-rehab. & $226(113)$ & $179(74)$ & $235(137)$ & $295(82)$ & 258 (109) \\
\hline Post-rehab. & 339 (134) & $293(97)$ & $350(160)$ & $413(120)$ & $358(139)$ \\
\hline Difference & $113(40)$ & $114(58)$ & $116(65)$ & $118(43)$ & $100(35)$ \\
\hline$P$-value & $<0.001$ & 0.006 & 0.061 & 0.157 & 0.301 \\
\hline \multicolumn{6}{|c|}{ Distance on treadmill (m) } \\
\hline Pre-rehab. & $120(80)$ & $114(66)$ & $135(106)$ & $105(51)$ & $99(32)$ \\
\hline Post-rehab. & $387(205)$ & 371 (199) & $386(264)$ & $358(100)$ & $470(43)$ \\
\hline Difference & $268(163)$ & $257(163)$ & $251(170)$ & $253(87)$ & $370(126)$ \\
\hline$P$-value & $<0.001$ & 0.001 & 0.004 & 0.004 & $<0.001$ \\
\hline \multicolumn{6}{|c|}{ Distance on bicycle (m) } \\
\hline Pre-rehab. & $1041(440)$ & $1031(358)$ & 1054 (508) & $1223(630)$ & $845(216)$ \\
\hline Post-rehab. & 2865 (1404) & $2532(1120)$ & 3035 (1756) & 3195 (1011) & 2898 (1475) \\
\hline Difference & $1824(1156)$ & $1503(962)$ & $1981(1294)$ & $1973(678)$ & 2052 (799) \\
\hline$P$-value & $<0.001$ & 0.004 & $<0.001$ & 0.016 & 0.331 \\
\hline \multicolumn{6}{|c|}{ Distance on ergometer (m) } \\
\hline Pre-rehab. & $526(154)$ & $555(136)$ & $560(179)$ & $430(111)$ & $425(100)$ \\
\hline Post-rehab. & $1392(665)$ & $1238(522)$ & $1400(829)$ & 1643 (528) & $1540(663)$ \\
\hline Difference & $867(602)$ & $683(438)$ & $840(602)$ & $1213(438)$ & $1115(415)$ \\
\hline$P$-value & $<0.001$ & $<0.001$ & 0.002 & 0.004 & 0.016 \\
\hline \multicolumn{6}{|c|}{ Emergency department visits (no.) } \\
\hline Pre-rehab. & $2.5(2.9)$ & $1.3(1.9)$ & $3.1(2.3)$ & $4.5(5.8)$ & $1.8(1.7)$ \\
\hline Post-rehab. & $0.9(1.2)$ & $0.6(0.9)$ & $1.2(1.1)$ & $1.3(1.9)$ & $0.8(0.9)$ \\
\hline Difference & $-1.1(1.7)$ & $-0.7(0.8)$ & $-1.9(1.4)$ & $-3.3(1.6)$ & $-1.0(0.4)$ \\
\hline$P$-value & 0.005 & 0.280 & 0.012 & 0.327 & 0.343 \\
\hline \multicolumn{6}{|c|}{ Outpatient department visits (days) } \\
\hline Pre-rehab. & $5.3(2.1)$ & $4.7(2.7)$ & $5.3(1.8)$ & $6.8(1.5)$ & $6.0(1.4)$ \\
\hline Post-rehab. & $2.8(0.9)$ & $2.7(0.6)$ & $2.5(0.9)$ & $3.3(0.9)$ & $3.5(1.0)$ \\
\hline Difference & $-2.6(1.8)$ & $-1.9(1.6)$ & $-2.8(1.7)$ & $3.5(1.2)$ & $-2.5(0.9)$ \\
\hline$P$-value & $<0.001$ & 0.033 & $<0.001$ & 0.007 & 0.028 \\
\hline \multicolumn{6}{|c|}{ Short-acting bronchodilator inhalers (no.) } \\
\hline Pre-rehab. & $7.3(5.1)$ & $4.2(3.5)$ & $10.0(5.8)$ & $8.0(1.8)$ & $6.3(3.1)$ \\
\hline Post-rehab. & $3.2(2.4)$ & $1.7(2.0)$ & $4.7(2.2)$ & $3.0(1.4)$ & $2.5(1.7)$ \\
\hline Difference & $-4.1(2.4$ & $-2.5(1.8)$ & $-5.3(4.0)$ & $-5.0(1.7)$ & $-3.6(1.3)$ \\
\hline$P$-value & $<0.001$ & 0.492 & 0.005 & 0.005 & 0.078 \\
\hline \multicolumn{6}{|c|}{ Cumulative prednisone dose (mg) } \\
\hline Pre-rehab. & $117(162)$ & $41(92)$ & $143(160)$ & $160(194)$ & $179(260)$ \\
\hline Post-rehab. & $33(76)$ & $21(46)$ & $56(106)$ & $25(50)$ & $0(0)$ \\
\hline Difference & $-84(126)$ & $-25(25)$ & $-87(78)$ & $-135(59)$ & $-194(92)$ \\
\hline$P$-value & 0.011 & 0.516 & 0.115 & 0.225 & 0.187 \\
\hline \multicolumn{6}{|c|}{ Antibiotic courses (no.) } \\
\hline Pre-rehab. & $2.0(2.2)$ & $2.1(2.8)$ & $2.2(1.9)$ & $2.0(2.2)$ & $1.3(1.5)$ \\
\hline Post-rehab. & $0.9(1.1)$ & $0.8(1.2)$ & $1.2(1.2)$ & $1.0(1.4)$ & $0.5(0.6)$ \\
\hline Difference & $-1.1(1.2)$ & $-1.3(1.1)$ & $-1.0(1.4)$ & $-1.1(1.6)$ & $-0.8(0.4)$ \\
\hline$P$-value & 0.016 & 0.181 & 0.112 & 0.468 & 0.387 \\
\hline
\end{tabular}

$S D=$ standard deviation. 
of short-acting bronchodilator inhalers, prednisone and antibiotics.

Although the current study showed measurable benefits in a group of patients with CLD other than COPD, a few limitations need to be considered. This was a single-centre study, as our pulmonary rehabilitation centre is the first and only place in the country that provides this service [21]. There were a small numbers of patients in each category, especially scoliosis and asthma, and a larger study is needed to confirm the results. Additionally, the patients included had different diseases, which limit the use of additional outcomes. Finally, quality of life measures were not included because a validated instrument was not available in Arabic until late 2006.

In conclusion, there were improvements in functional exercise capacity after the completion of a pulmonary rehabilitation programme in patients with CLD other than COPD, accompanied by lower rates of utilization of health care resources. Health care utilization patterns and medication use of patients prior to pulmonary rehabilitation may help to predict their adherence to the pulmonary rehabilitation programme.

\section{Acknowledgements}

The author would like to thank Dr Hani Tamim from the Medical Education Department, College of Medicine, King Saud bin Abdulaziz University for Health Sciences for analysis support, and Naifa Alaida and Einas Khalifa from the Pulmonary Rehabilitation Centre, King Abdulaziz Medical City for providing patient data.

\section{References}

1. Mannino DM et al. Chronic obstructive pulmonary disease surveillance-United States, 1971-2000. MMWR. Morbidity and Mortality Weekly Report, 2002, 51:1-16.

2. Nici L et al. American Thoracic Society/European Respiratory Society statement on pulmonary rehabilitation. American Journal of Respiratory and Critical Care Medicine, 2006, 173:1390-1413.

3. Lacasse $Y$ et al. Pulmonary rehabilitation for chronic obstructive pulmonary disease. Cochrane Database of Systematic Reviews, 2006, 18:CD003793.

4. Laviolette L et al. Assessing the impact of pulmonary rehabilitation on functional status in COPD. Thorax, 2008, 63:115-121.

5. Ando $\mathrm{M}$ et al. The effect of pulmonary rehabilitation in patients with post-tuberculosis lung disorder. Chest, 2003, 123:1988-1995.

6. Nishiyama O et al. Effects of pulmonary rehabilitation in patients with idiopathic pulmonary fibrosis. Respirology, 2008, 13:394-399.

7. Casaburi R. Limitation to exercise tolerance in chronic obstructive pulmonary disease. look to the muscles of ambulation. American Journal of Respiratory and Critical Care Medicine, 2003, 168:409-414.

8. Bradley J, Moran F, Greenstone M. Physical training for bronchiectasis (Cochrane Review). In: The Cochrane Library, Issue 1. Oxford, Update Software, 2003.

9. California Pulmonary Rehabilitation Collaborative Group. Effects of pulmonary rehabilitation on dyspnea, quality of life and healthcare costs in California. Journal of Cardiopulmonary Rehabilitation, 2004, 24:52-62.

10. Wijkstra PJ et al. Relation of lung function, maximal inspiratory pressure, dyspnoea, and quality of life with exercise capacity in patients with chronic obstructive pulmonary disease. Thorax, 1994, 49:468-472.
11. Sullivan S, Ramsey S, Lee T. The economic burden of COPD. Chest, 2000, 117:S5-S9.

12. Alamoudi OS. Prevalence of respiratory diseases in hospitalized patients in Saudi Arabia: a 5 years study 1996-2000. Annals of Thoracic Medicine, 2006, 1:76-80.

13. American Thoracic Society. Standardization of spirometry. American Journal of Respiratory and Critical Care Medicine, 1995, 152:1107-1136.

14. Brooks DS. Solway, Gibbons WJ. ATS statement on six-minute walk test. American Journal of Respiratory and Critical Care Medicine, 2003, 167:1287.

15. Holland A et al. Short term improvement in exercise capacity and symptoms following exercise training in interstitial lung disease. Thorax, 2008, 63:549-554.

16. Ferreira $\mathrm{A}$ et al. Pulmonary rehabilitation in interstitial lung disease: benefits and predictors of response. Chest, 2009, 135:442-447.

17. Markovitz GH, Cooper CB. Exercise and interstitial lung disease. Current Opinion in Pulmonary Medicine, 1998, 4:272-280.

18. Skeletal muscle dysfunction in chronic obstructive pulmonary disease: a statement of the American Thoracic Society and European Respiratory Society. American Journal of Respiratory and Critical Care Medicine, 1999, 159:S1-S40.

19. Al Moamary MS. Experience with pulmonary rehabilitation in a tertiary care center in Saudi Arabia. Saudi Medical Journal, 2008, 29:477-482.

20. Alves $V$, Stirbulov R, Avanzi O. Impact of a physical rehabilitation program on the respiratory function of adolescents with idiopathic scoliosis. Chest, 2006, 130:500-505.

21. Al-Moamary MS. Health care utilization among chronic obstructive pulmonary disease patients and the effect of pulmonary rehabilitation. Medical Principles and Practice, 2010, 205, 19:373-378. 